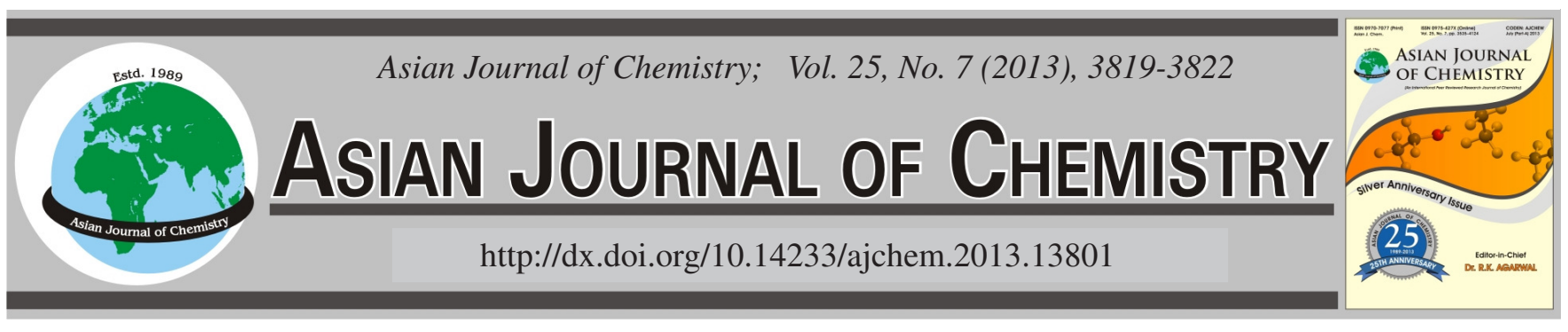

\title{
Determination of Humic Acid in Loess by Potassium Permanganate Oxidization Flow-Injection Chemiluminescence Method
}

\author{
Shengke Yang*, Binbin Zhang, Yue Zhao and Jing Chen
}

Key Laboratory of Subsurface Hydrology and Ecology in Arid Areas, Ministry of Education, Department of Environmental Science and Engineering, Chang'an University, Xi'an, P.R. China

*Corresponding author: E-mail: ysk110@126.com; cj120325@gmail.com

(Received: 28 March 2012;

Accepted: 14 January 2013)

AJC-12701

\begin{abstract}
In this study, potassium permanganate was found to be capable of oxidizing humic acid and causing chemiluminescence reaction. The chemiluminescence dynamic curve of $\mathrm{KMnO}_{4}$-humic acid system was drawn, the reaction conditions were optimized and a new chemiluminescence analysis method to determine humic acid in loess was established with the linear range from $1 \times 10^{-1}$ to $1 \times 10^{2} \mathrm{mg} / \mathrm{L}(\mathrm{R}=$ 0.9989 ) and detection range of $8 \times 10^{-8} \mathrm{~g} / \mathrm{mL}$. Eleven replicate determinations were conducted on humic acid with the concentration of $20 \mathrm{mg} / \mathrm{L}$ and the calculated relative standard deviation (RSD) was $2.98 \%$. By taking the loess from the Loess Plateau as the determination object, the extraction conditions of humic acid from loess were confirmed as follows: the mixture of $0.1 \mathrm{~mol} / \mathrm{L}$ sodium pyrophosphate and $0.1 \mathrm{~mol} / \mathrm{L}$ sodium hydroxide was used as extract; the water-soil ratio was $1: 30$ and the extraction time was $0.5 \mathrm{~h}$. Humic acid in loess obtained from five different regions was determined and standard recovery tests were conducted at the same time, with the standard recovery rate of the samples between 94.0 and $114 \%$.
\end{abstract}

Key Words: Chemiluminescence, Humic acid, Potassium permanganate.

\section{INTRODUCTION}

Humic acid is a type of natural polymer organic substances widely existed in nature ${ }^{1,2}$. Its complicated structure and many kinds of active functional groups enable it to react with many organic and inorganic substances ${ }^{3}$. It was found in recent researches ${ }^{4-6}$ that in the ecological environment on the earth, humic acid was distributed in nearly all soils, water bodies (including rivers, lakes and oceans) and sediments. Since humic acid contains many kinds of functional groups, like phenolic hydroxyl group, alcoholic hydroxyl group, carboxylic acid, aldehyde, ketone and ether, it possesses very high reactivity (like adsorption, complexion, reduction-oxidation and photochemical action) and can react with metal ions, oxides, hydroxides, mineral substances, organic substances and toxic active pollutants etc., forming water-soluble or water-insoluble substances with quite different chemical and biological properties. Therefore, the determination of humic acid which widely exists in natural water bodies and soils is of significance for in-depth study on the migration of pollutants in water and soil environments.

At present, methods for testing humic acid are mainly potassium dichromate oxidation-volumetric method ${ }^{7}$, oxygen demand determination method $^{8}$, ultraviolet spectrophotometry ${ }^{9}$ and remote sensing method ${ }^{10}$. Each method has its own drawbacks, e.g., the potassium dichromate oxidation-volumetric method has drawbacks of complex operation and long duration, difficult identification of titration end point, bad repeatability and low analysis efficiency ${ }^{7}$. Due to the advantages of simple operation, low instrument cost, sensitivity, rapidity and good repeatability etc., flow-injection chemiluminescence method has been used for determination of humic acid Ding Baojun ${ }^{4}$ indicated that hydroquinone could sensitize chemiluminescence of luminal- $\mathrm{NaIO}_{4}$, which could be obviously inhibited by humic acid, thus a method to determine humic acid in natural water bodies by flow-injection chemiluminescence method was established. However, the system of this determination method was complex. It was found in the researches of Michafowski ${ }^{11}$ that, N-bromosuccinimide could oxidize humic acid directly and generate strong chemiluminescence signals under alkaline conditions, from which a method to determine humic acid in water bodies by flow-injection chemiluminescence method was derived. This method was further applied by Fang Luqiu ${ }^{12-14}$ in the determination of humic acid in soils. However, as a hazardous organic substance which causes high irritation to skins and mucous membrane, N-bromosuccinimide, when used in large amount, would be harmful to the environment. Moreover, its insolubility in water causes lots of inconveniences 
in actual application. In addition, research data on humic acid in soils shows that ${ }^{15,16}$, soils of different types have different structures due to their forming conditions and environment, therefore the content of humic acid and its combining capacity with soils vary a lot. Therefore it could be seen clearly that, in order to determine humic acid in soils precisely, the influences of types and structure characteristics of soils, extraction method of humic acid (like selection of extract, solid-liquid ratio and extraction time) and other factors on the determination results should be taken into consideration. For this reason, five kinds of representative subtype soil of loess taken from the Loess Plateau in China were selected and a method for determining humic acid content in loess was studied on the basis of the simple chemiluminescence method for determination of the humic acid system.

It was found in experiments that, $\mathrm{KMnO}_{4}$ could be used in humic acid system to generate strong chemiluminescence signals under alkaline conditions. By integrating flow-injection technology, extraction method for humic acid could be optimized so as to establish the chemiluminescence analysis method for determination of humic acid in loess. This method was used for analysis and recovery of loess samples, with satisfactory results.

\section{EXPERIMENTAL}

IFFM-E type flow injection chemiluminescence analyzer (Xi'An Ruimai Electronic Technology Co., Ltd.); IFFS-A type multi-functional chemiluminescence detector (Xi'An Ruimai Electronic Technology Co. Ltd.); CS101-AB type electrothermal blowing dry box (Chongqing Test Equipment Factory); FA2004 type electronic precision balance (Shanghai Precision $\&$ Scientific Instrument Co. Ltd.); constant temperature oscillator (Beijing Greenworld Garden Environmental Technology Developing Co., Ltd.).

Preparation of standard stock solution of humic acid with a concentration of $1 \times \mathbf{1 0}^{-5} \mathrm{~g} / \mathrm{L}$ : $100 \mathrm{mg}$ humic acid was dissolved in $0.1 \mathrm{~mol} / \mathrm{L} \mathrm{NaOH}$ and then diluted to $1000 \mathrm{~mL}$ with $\mathrm{NaOH}$ of the same concentration and the required concentrations were achieved through step-by-step dilution with 0.1 $\mathrm{mol} / \mathrm{L} \mathrm{NaOH}$ when it was used.

Preparation of stock solution of potassium permanganate with a concentration of $5.0 \times \mathbf{1 0}^{-3} \mathbf{~ m o l} / \mathrm{L}: 0.3950 \mathrm{~g}$ potassium permanganate was dissolved in water and diluted to $500 \mathrm{~mL}$ with water and required concentrations were diluted step by step with water when it was used.

Preparation of extract-mixture of sodium pyrophosphate with sodium hydroxide: $89.2 \mathrm{~g}$ of sodium pyrophosphate $\left(\mathrm{Na}_{4} \mathrm{P}_{2} \mathrm{O}_{7} \cdot 10 \mathrm{H}_{2} \mathrm{O}\right)$ and $8 \mathrm{~g} \mathrm{NaOH}$ were weighted and dissolved in water, respectively, then they were mixed and diluted precisely to $2 \mathrm{~L}$.

All the above reagents were analytical reagents and the water used in the experiment was double distilled water.

Sample collection: The grain sizes of loess in the Loess Plateau change from small to large successively from the south to the north of Shaanxi province. Therefore, with the valley of the Wei River as the starting point, samples were taken successively from floodplain of the Wei River, first terrace-loess, second terrace-loess, loess terrace-loess and sandstorm beach in north Shaanxi-loess from the south to the north. Then the samples were dried by natural air at room temperature and passed through a 60 mesh sieve after being crushed, which was then put into ground bottles and sealed and stored at 2-8 ${ }^{\circ} \mathrm{C}$ for further use.

Pretreatment of samples: Soil sample of $5 \mathrm{~g}$ was weighted and put into $150 \mathrm{~mL}$ iodine flasks, extract was added according to a certain water/soil ratio and then the iodine flasks were put onto the oscillator to be shaken at the speed of 120 times/min at room temperature $\left(25^{\circ} \mathrm{C}\right)$. Samples were taken, respectively at different time and determined by chemiluminescence method.

Testing method: The flow path of chemiluminescence determination is shown in Fig. 1. Water solution in path $b$ and potassium permanganate solution in path $\mathrm{c}$ were mixed by a mixer and injected through the sampling inlet valve. Then the mixed liquid performed chemiluminescence reaction with the sample solution in path c. Chemiluminescence signal I was recorded and $\Delta \mathrm{I}$, which was the difference between I and blank signal $\mathrm{I}_{0}$, was used for quantitative analysis.

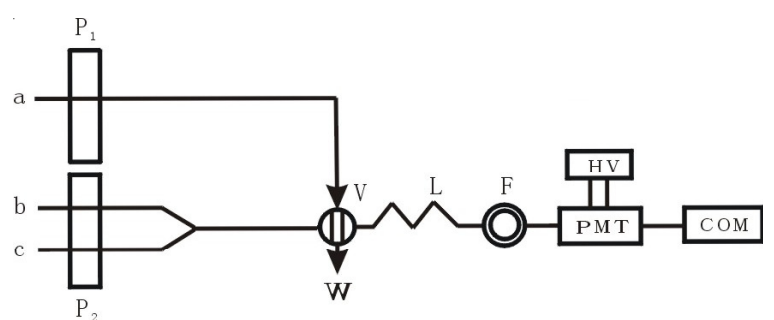

Fig. 1. Schematic diagram of flow injection chemiluminescence analysis. a: Sample, Humic acid; b: distilled water; c: $5.0 \times 10^{-3} \mathrm{~mol} / \mathrm{L} \mathrm{KMnO}_{4}$ solution; $\mathrm{P}_{1}, \mathrm{P}_{2}$ : Peristaltic pump; V: Sampling inlet valve; L: Mixing tube; F: Flowing cell; HV: High voltage; PMT: Photomultiplier tube; COM: (Computer); W: Waste

\section{RESULTS AND DISCUSSION}

Chemiluminescence dynamic curve of $\mathrm{KMnO}_{4}$-humic acid system: Chemiluminescence behaviours of humic acid and its dynamic properties were studied by the static measurement system in which IFFM-E type flow-injection chemiluminescence analyzer was used. The results were shown in Fig. 2 , by comparing the chemiluminescence reaction curve which

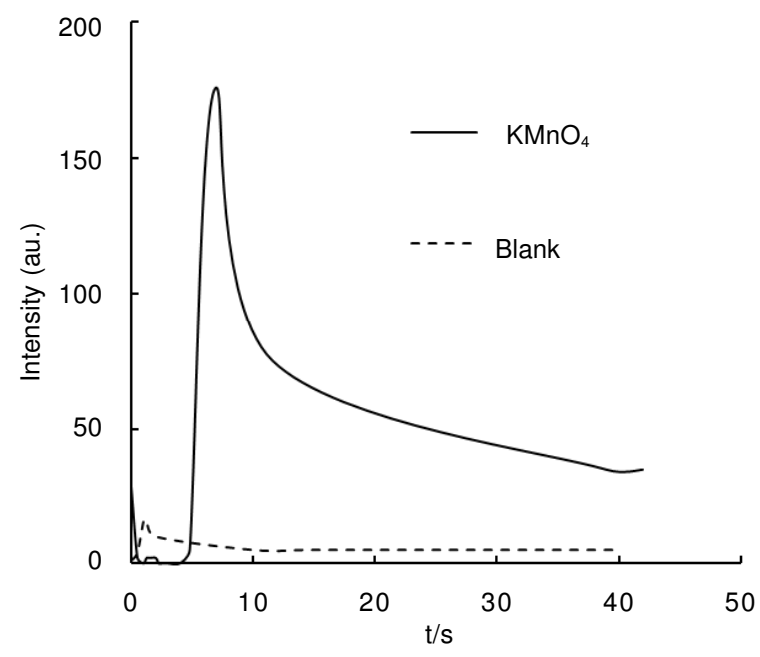

Fig. 2. Dynamic curve of humic acid- $\mathrm{KMnO}_{4}$ system 
happened after $0.5 \mathrm{~mL}$ of $1.0 \times 10^{-2} \mathrm{~mol} / \mathrm{L}$ potassium permanganate was injected into $0.5 \mathrm{~mL} 20 \mathrm{mg} / \mathrm{L}$ humic acid solution with the luminescence curve of blank experiment, it could be seen that potassium permanganate could react with humic acid and generate chemiluminescence with good response. A simple method to determine humic acid was established.

\section{Optimization of determination conditions}

Influence of negative high voltage and gain on the system: The variation range of chemiluminescence intensity was influenced by the negative high voltage and gain of the instrument. Too large negative high pressure and gain might cause chemiluminescence intensity to exceed its limit easily, while too low would result in unobvious changes in chemiluminescence intensity. Humic acid with the concentration of $20 \mathrm{mg} / \mathrm{L}$ was determined with the negative high pressure between -600 and $-900 \mathrm{~V}$ and gain at 1,2 and 4, respectively. When the gain was 1 and the negative high voltage was -900 $\mathrm{V}$, the signal was the strongest.

Influence of pump speed on the system: During flow injection analysis, pump speed was of significant importance for the rapid detection of luminescence phenomena by the detector and it would even affect the sensitivity of determination. Among the pump speeds, the main pump speed had the greater influence; therefore, main pump speed was adjustable while the subsidiary pump speed was maintained unchanged. Pump speed was set within the range of 30 and $90 \mathrm{r} / \mathrm{min}$ while the concentration of humic acid was $20 \mathrm{mg} / \mathrm{L}$. The results showed that, signal was the strongest when the main pump speed was $90 \mathrm{r} / \mathrm{min}$ and subsidiary pump speed was $50 \mathrm{r} / \mathrm{min}$.

Influence of the concentration of $\mathrm{KMnO}_{4}$ on the system: The influence of $1.0 \times 10^{-5}-5.0 \times 10^{-2} \mathrm{~mol} / \mathrm{L}$ potassium permanganate on determination results was tested. The results showed that, signal was the strongest when the concentration of potassium permanganate was $5.0 \times 10^{-3} \mathrm{~mol} / \mathrm{L}$.

Influence of the concentration of $\mathrm{NaOH}$ on the system: In the reactions, alkalinity of the system was adjusted by changing the concentration of $\mathrm{NaOH}$ in humic acid. The influence of $0.01-0.5 \mathrm{~mol} / \mathrm{L} \mathrm{NaOH}$ in humic acid on determination results was investigated. The results showed that, when the concentration of $\mathrm{NaOH}$ was $0.1 \mathrm{~mol} / \mathrm{L}$, the signal was the strongest.

Standard curve, precision and detection limit of the method: Under optimal experiment conditions, humic acid solution within the concentration range from $1 \times 10^{-1}-1 \times 10^{2}$ $\mathrm{mg} / \mathrm{L}$ showed good linear relationship with chemiluminescence intensity $\left(\Delta \mathrm{I}=\mathrm{I}-\mathrm{I}_{0}\right.$ : quantitative $\Delta \mathrm{I}$ was the difference between chemiluminescence signal I and blank signal $\mathrm{I}_{0}$ ). Correlation coefficient $\mathrm{R}=0.9989$. The linear regression equation was $\Delta \mathrm{I}$ $=4.2492 \rho+6.0754$ ( $\rho$ was the concentration of humic acid solution, $\mathrm{mg} / \mathrm{L}$ ). Eleven times of replicate determinations were conducted on the humic acid with the concentration of $20 \mathrm{mg} / \mathrm{L}$, with the calculated relative standard deviation (RSD) of 2.98 $\%$. According to the recommendations of IUPAC, the calculated detection limit of the method was $8 \times 10^{-8} \mathrm{~g} / \mathrm{mL}$.

Optimization of extraction conditions of soil samples: Extraction methods of humic acid from soils include diluted alkaline method and ASI method etc. Among all, the diluted alkaline $\left(\mathrm{NaOH}, \mathrm{Na}_{4} \mathrm{P}_{2} \mathrm{O}_{7}, \mathrm{NaF}\right.$ or their mixture etc.) method is predominant.
For the same soil ${ }^{15}$, humic acid obtained by extraction using various inorganic extractants vary a lot. It is shown by researches that, compared with the humic acid extracted using $\mathrm{Na}_{4} \mathrm{P}_{2} \mathrm{O}_{7}$, the humic acid extracted using $\mathrm{NaOH}$ possesses slightly higher carbon content, lower oxygen content and slightly higher $\mathrm{H} / \mathrm{C}$ atom ratio. It could be seen that, components of the extracted humic acid were greatly affected by the extract. Therefore, in order to extract all the humic acid from the soil, the mixture of $0.1 \mathrm{~mol} / \mathrm{L}$ sodium pyrophosphate and $0.1 \mathrm{~mol} / \mathrm{L}$ sodium hydroxide was used as the extract and the influences of different water/soil ratios and time on the extraction rate were investigated.

Influence of extraction time on the extraction amount of humic acid: Determination of humic acid in the samples was somehow influenced by the extraction time; therefore, experiments were conducted to investigate the influence of different extraction time on the extraction amount of humic acid.

Extract was added into the five loess samples with the water/soil ratio of 1:30. Then the mixer was put into the oscillating dishes and oscillated for 5, 10, 20, 30, 60 and $90 \mathrm{~min}$, respectively. After that, samples were tested and taken and the results are shown in Fig. 3.

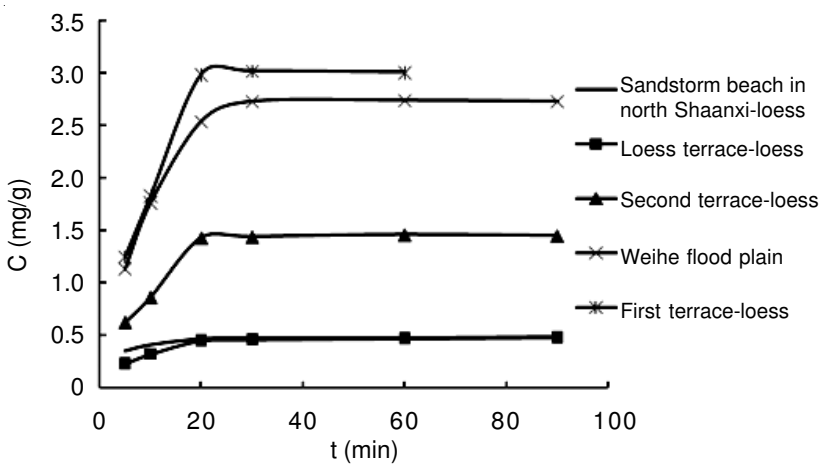

Fig. 3. Influence of extraction time on the concentration of humic acid

When the extraction time increased gradually, the amount of humic acid extracted from the soil samples increased gradually. The extraction time had little influence on the soil samples with small humic acid content, but when the soil had higher humic acid content, enough time would be important to maintain high extraction rate. After $20 \mathrm{~min}$, the extraction amount of humic acid was stabilized gradually and $0.5 \mathrm{~h}$ was selected as the optimal extraction time.

Influence of water/soil ratio on the extraction amount of humic acid: Different water/soil ratios would also affect the concentration of humic acid extracted from the samples. The influence of 6 water/soil ratios on the extraction amount of humic acid was tested.

It could be seen from Fig. 4 that, different water/soil ratios would yield different humic acid extraction rates and the influence on different soils was also different. The extraction rate of humic acid was relatively stable when water/soil ratio was 1:20. It could be seen from the experiment that, the optimal water/soil ratio in the samples was 1:30.

Determination of standard recovery rate of the samples: The soil samples were pretreated by extraction for $0.5 \mathrm{~h}$ at the 
TABLE-1

DETERMINATION RESULTS OF STANDARD ADDITION METHOD OF ACTUAL SAMPLES $(\mathrm{n}=5)$

\begin{tabular}{lcccc}
\hline \multicolumn{1}{c}{ Sample } & Initial quantity $(\mathrm{mg} / \mathrm{L})$ & Add scalar $(\mathrm{mg} / \mathrm{L})$ & Recovery rate $(\%)$ & RSD $(\%)$ \\
\hline Wei River floodplain & 42.91 & 27.27 & 96.8 & 0.6 \\
First terrace-loess & 45.46 & 36.36 & 94.0 & 2.1 \\
Second terrace-loess & 18.4 & 13.64 & 104.8 & 1.4 \\
Loess terrace -loess & 6.18 & 9.09 & 113.6 & 1.2 \\
Sandstorm beach in north Shaanxi-loess & 4.97 & 4.55 & 114 & 1.4 \\
\hline
\end{tabular}

TABLE-2

ANALYSIS RESULTS OF THE SAMPLES

\begin{tabular}{lccc}
\hline \multicolumn{1}{c}{ Sample } & Measured quantity by our method $(\mathrm{mg} / \mathrm{kg})$ & Average value $(\mathrm{mg} / \mathrm{kg})$ & Chemistry analytic $(\mathrm{mg} / \mathrm{kg})$ \\
\hline Wei river floodplain & $2.74,2.67,2.73,2.74,2.73$ & $2.72 \pm 0.018$ & 2.87 \\
First terrace-loess & $2.98,3.07,3.02,3.01,3.05$ & $3.03 \pm 0.012$ & 3.26 \\
Second terrace-loess & $1.46,1.49,1.44,1.46,1.45$ & $1.46 \pm 0.013$ & 1.37 \\
Loess terrace -loess & $0.47,0.48,0.46,0.47,0.48$ & $0.47 \pm 0.018$ & 0.43 \\
Sandstorm beach in north Shaanxi-loess & $0.49,0.47,0.48,0.48,0.49$ & $0.48 \pm 0.017$ & 0.52 \\
\hline
\end{tabular}

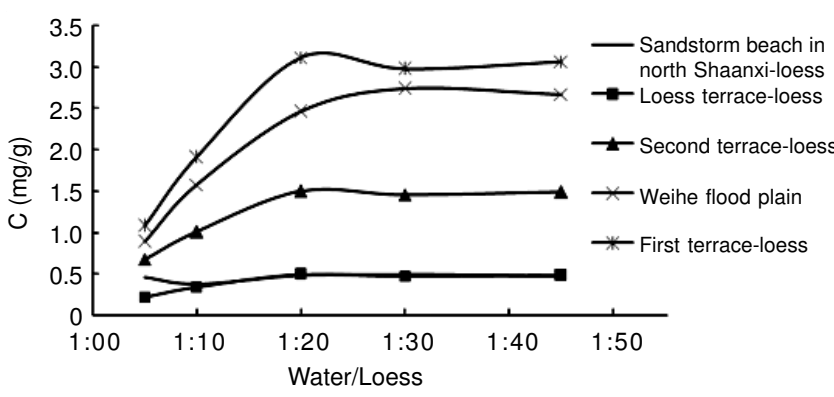

Fig. 4. Influence of water/soil ratio on the concentration of humic acid

optimal water/soil ratio of 1:30. The contents of humic acid in the clear liquid were determined after the samples were pretreated. Meanwhile, the standard recovery experiment was conducted. The results are shown in Table-1. It was shown by the determination results that, the standard recovery rates of the samples were located between 94.0 and $114 \%$. Analysis the determination results of soil samples from loess zone, they are shown in Table-2.

\section{Conclusion}

A chemiluminescence analysis method to determine humic acid in loess was established by oxidizing humic acid directly using $\mathrm{KMnO}_{4}$ to generate strong chemiluminescence signals under alkaline conditions and integrating with flowinjection technology. Humic acid in loess could be more effectively extracted by using the mixture of $0.1 \mathrm{~mol} / \mathrm{L}$ sodium pyrophosphate and $0.1 \mathrm{~mol} / \mathrm{L}$ sodium hydroxide as the extract and taking the water/soil ratio of 1:30 and extraction time of $0.5 \mathrm{~h}$. Loess contained little but different humic acid, with the determination range from $4.97-45.46 \mathrm{mg} / \mathrm{g}$.

\section{ACKNOWLEDGEMENTS}

The support of Program for the National Natural Science Foundation of China (No. 2097024) and Changjiang Scholars and Innovative Research Team in University of Ministry of Education of China (IRT0811) is acknowledged.

\section{REFERENCES}

1. K. Ghosh and M. Chnitzer, Soil Sci., 129, 266 (1980).

2. P. Zheng, Production and Application of Humic Acid of Coal, Beijing, Chemical Industry Press, pp. 60-69 (1991).

3. K.B. Li and J.S. Xi, Chem. Ind., 27, 11 (1998).

4. B.J. Ding, F.L. Yang, Z.L. Zhu, G. Xiao and L.J. Cui, Spectrosc. Spectral Anal., 28, 530 (2008).

5. H.S. Zhuang, Q.E. Wang and F. Wu, Spectrosc. Spectral Anal., 24, 927 (2004).

6. L.Y. Du, N.N. Ji, S.H. Wang and H.S. Zhuang, Spectrosc. Spectral Anal., 25, 1943 (2005).

7. S.D. Bao, Soil Agro-Chemistry Analysis, Agriculture Press, Beijing, edn. 3, pp. 30-38 (2000).

8. Q.F. Yin, K.X. Wei and D.H. Qi, J. Huaiyin Teachers College, 5, 57 (2006).

9. B. Yuan, S. Lv and W.H. Zhang, Ind. Water Treat., 30, 75 (2010).

10. E.H. Kapaaanoaa et al., Agric. Praeger New Technol. New Method, 62, 33 (1996)

11. J. Michafowski, P. Haaburda and A. Kojo, Anal. Chim. Acta, 438, 143 (2001).

12. L.Q. Fang, Environ. Monitoring China, 23, 26 (2007).

13. L.Q. Fang, Z.P. Wang, Z.F. Fu, W.F. Luo and Z.J. Zhang, J. Instrum. Anal., 22, 25 (2003).

14. L.Q. Fang, Z.P. Wang, Z.F. Fu, W.F. Luo and Z.J. Zhang, J. Southwest China Normal Univ. (Nat. Sci.), 28, 603 (2003).

15. C.S. Liang, Z. Dang and C.Q. Liu, Chin. J. Anal. Chem., 34, 288 (2006).

16. Y.H. Feng, Y. Zhang, Q. Zou, C.M. You and J.H. Yang, J. Anhui Agric. Sci., 35, 6496 (2007). 